\title{
Characterization of the hemin-binding property of Porphyromonas endodontalis
}

\author{
Eun Jeong Kim ${ }^{1}$ and Si Young Lee ${ }^{2 \star}$
}

${ }^{1}$ Master's Student, College of Dentistry, Gangneung-Wonju National University, Gangneung, Republic of Korea

${ }^{2}$ Professor, Department of Microbiology and Immunology, College of Dentistry, Research Institute of Oral Science, Gangneung-Wonju National University, Gangneung, Republic of Korea

Porphyromonas endodontalis, found in the root canal of teeth, requires iron for growth. However, the mechanism of iron uptake in $P$. endodontalis remains unclear. The ability of bacteria to utilize heme compounds to acquire iron for growth has been reported in some pathogenic bacteria. In the present study, we analyzed the ability of $P$. endodontalis to obtain iron from heme compounds. Further, we investigated the hemin-binding characteristics of $P$. endodontalis and the relationship between hemin binding and Congo red binding. To confirm the bacterial growth in hemin-supplemented medium, iron was removed from the medium with an ironchelator, and hemin was supplemented to an iron-free medium. The hemin-binding characteristics of $P$. endodontalis were analyzed by incubating bacteria with hemin and measuring the optical density of the supernatant obtained via centrifugation, using hemin concentration standard curve. Although growth of $P$. endodontalis was not observed in the iron-depleted medium, it was observed in a hemin-supplemented medium. Further, hemin binding was dependent on the concentrations of hemin and bacteria. Hemin binding proceeded quickly in $P$. endodontalis, and the incubation temperature had no effect on this binding. Similar to hemin binding, Congo red binding of $P$. endodontalis was dependent on Congo red and bacterial concentrations. In addition, Congo red binding of $P$. endodontalis was inhibited by hemin prebinding. Hemin-agarose beads and SDS-PAGE were used to identify a $40-\mathrm{kDa}$ protein that could be involved in hemin binding. The results showed that $P$. endodontalis could bind to and use hemin to obtain the iron required for growth.

Key Words: Congo red; Hemin; Hemin binding protein; Porphyromonas endodontalis

(a) This is an open-access article distributed under the terms of the Creative Commons Attribution Non-Commercial License (http://creativecommons.org/licenses/by-nc/4.0) which permits unrestricted noncommercial use, distribution, and reproduction in any medium, provided the original work is properly cited.

\section{Introduction}

Iron is a nutrient essential for the growth of bacteria and is required for various biochemical and physiological responses [1]. Growth of pathogenic bacteria observed in the infected areas of animals [2] or humans [3] was severely limited when the availability of iron was limited. Therefore, the ability of bacteria to obtain iron in the host is likely to be involved in the survival of bacteria.

Pathogenic bacteria have diverse and sophisticated systems to obtain the iron required for growth, three mechanisms are known [4]. First, the iron transport system is the mechanism using siderophore. Many microorganisms not only synthesize the iron-chelator siderophore but also have

Received March 2, 2021; Revised [1] March 23, 2021; [2] April 9, 2021; Accepted April 24, 2021

*Corresponding author: Si Young Lee, Department of Microbiology and Immunology, College of Dentistry, Research Institute of Oral Science, Gangneung-Wonju National University, 7 Jukheon-gil, Gangneung 25457, Republic of Korea.

Tel: +82-33-640-2455, Fax: +82-33-642-6410, E-mail: siyoung@gwnu.ac.kr

Copyright @ 2021, Oral Biology Research Institute 
a specific transport system for transporting the ferric-siderophore complex (siderophore-Fe ${ }^{3+}$ ) into the cell [4-6]. As a second iron transport system, some bacteria can acquire iron from human iron binding proteins by specific recognition and transport systems. Iron binding proteins that can be used by pathogenic bacteria include transferrin found in serum and lactoferrin present on mucosal surface [7]. Transferrin or lactoferrin, coupled with iron, can transport iron into bacteria by binding to iron-inducible outer membrane proteins (OMPs) present in bacterial membranes. The third iron transport system uses heme and heme compounds. Heme and heme compounds can provide enough iron for the growth of bacteria [8]. Heme compounds include hemoglobin, haptoglobin, and hemopexin, which can supply iron to bacteria at low concentrations $(<10$ $\mu \mathrm{M})$ [8]. Porphyromonas gingivalis [8], Treponema denticola [9] and Aggregatibacter actinomycetemcomitans [10] are known to acquire iron by using heme compounds. In addition to oral bacteria, bacterial species such as Helicobacter pylori [11] and Vibrio cholera [12] are known to obtain iron using heme compounds.

Porphyromonas endodontalis is a black anaerobic coccobacillus suspected to play an important role in endodontic infection of teeth [13]. For cultivation of $P$. endodontalis, amino acids, reducing agents and heme compounds are required in a medium [13]. In addition, Porphyromonas spp. accumulate high concentrations of hemin to the extent that colony appears black in blood agar.

Previous studies have shown that the ability to bind to hemin in certain pathogenic bacteria is strongly associated with their ability to bind Congo red [14-16]. In a study of oral spirochetes (Treponema denticola, Treponema vincentii, and Treponema socranskii), the hemin binding property of bacteria was reported to be associated with Congo red binding [15].

In this study, we investigated whether the mechanism of $P$. endodontalis to acquire iron includes hemin binding properties and whether hemin binding is related to Congo red binding.

\section{Materials and Methods}

\section{Bacterial strains and growth conditions}

P. endodontalis ATCC 35406 was cultured for 48 hours in Brain Heart Infusion (BHI) medium supplemented with hemin (Sigma-Aldrich, Saint Louis, MO, USA) (5 mg/L), menadione (Sigma-Aldrich) $(10 \mathrm{mg} / \mathrm{L})$ and yeast extract (Becton Dickinson biosciences, Franklin Lake, NJ, USA) (5 g/L) at $37^{\circ}$ $\mathrm{C}$ under an anaerobic condition (Bactron Anaerobic Chamber, Sheldon Manufacturing Inc., Cornelius, OR, USA) with $90 \% \mathrm{~N}_{2}, 5 \% \mathrm{CO}_{2}, 5 \% \mathrm{H}_{2}$.

\section{Growth tests}

In order to investigate the use of hemin for P. endodontalis growth, the growth of bacteria was investigated by adding hemin to the iron-free medium. Bacterial growth experiments were carried out using the procedures described by Eichenbaum et al. [17]. BHI medium containing menadione (10 mg/L), 5\% yeast extract and $0.1 \mathrm{M}$ Tris $\mathrm{HCl}$ was adjusted to $\mathrm{pH} 7.3$. The iron in the medium was depleted by the addition of $30 \mathrm{mM}$ nitrilotriacetic acid trisodium salt (NTA) as an iron chelator. $1 \mathrm{mM}$ each of $\mathrm{MgCl}_{2}, \mathrm{CaCl}_{2}, \mathrm{MnCl}_{2}$ and $\mathrm{ZnCl}_{2}$ was added to the medium. In addition, hemin $(10 \mu \mathrm{g} / \mathrm{mL}$ or $25 \mu \mathrm{g} / \mathrm{mL})$ was added to NTA-treated medium. As a control, BHI medium ( $\mathrm{pH} 7.3$ ) containing menadione $(10 \mathrm{mg} / \mathrm{L})$ and yeast extract $(5 \mathrm{~g} /$ L) prepared using $0.1 \mathrm{M}$ Tris- $\mathrm{HCl}$ without addition of NTA and hemin, was used. $P$. endodontalis was cultured in each medium at $37^{\circ} \mathrm{C}$ under an anaerobic condition (Bactron Anaerobic Chamber) with $90 \% \mathrm{~N}_{2}, 5 \% \mathrm{CO}_{2}$, and $5 \% \mathrm{H}_{2}$. $\mathrm{OD}$ values were measured at $660 \mathrm{~nm}$ at $0,9,24,33,48,57,72$, 81 , and 96 hours after incubation.

\section{Hemin binding and Congo red binding analysis}

To analyze the hemin binding of $P$. endodontalis, bacterial pellets were collected by centrifugation $\left(12,000 \times \mathrm{g}, 4^{\circ} \mathrm{C}\right.$, 10 minutes) after cultivating the bacteria for 48 hours. The bacterial pellet was washed twice with phosphate buffered saline (PBS) and then resuspended in PBS $\left(\mathrm{OD}_{660}=1.5\right.$; $[1 \times$ $10^{10}$ cells $/ \mathrm{mL}$ ). $1 \mathrm{~mL}$ of the bacterial suspension was in- 
cubated with $0.5 \mathrm{~mL}$ of hemin (final concentration $40 \mu \mathrm{g}$ / $\mathrm{mL}$ ) (Sigma-Aldrich) for 30 minutes in a $37^{\circ} \mathrm{C}$ water bath. The optical density (OD) of the supernatant was measured at $400 \mathrm{~nm}$ after centrifugation $\left(12,000 \times \mathrm{g}, 4^{\circ} \mathrm{C}, 10 \mathrm{~min}-\right.$ utes) [18]. The amount of hemin remaining in the supernatant was calculated from the concentration standard curve. The amount of hemin bound to the bacteria was calculated as the difference between the amount of hemin initially added and the amount remaining in the supernatant after the reaction [18].

In order to investigate the characteristics of hemin binding of $P$. endodontalis, hemin binding was analyzed under various conditions. First, to examine whether the hemin binding of $P$. endodontalis is dependent on the incubation temperature, hemin binding assay was performed at the incubation temperature of $4^{\circ} \mathrm{C}, 25^{\circ} \mathrm{C}$ and $37^{\circ} \mathrm{C}$. Second, to investigate whether the hemin binding of $P$. endodontalis varies with the incubation time, the hemin binding was analyzed by varying the incubation time to 1,10 , and 30 minutes. Third, the experiment was conducted in various concentrations of $P$. endodontalis ( $[0-20] \times 10^{9}$ cells $/ \mathrm{mL}$ ) to investigate whether the hemin binding of $P$. endodontalis was dependent on the concentration of bacteria. Finally, the experiment was performed in various hemin concentrations (final concentration $0-80 \mu \mathrm{g} / \mathrm{mL}$ ) to investigate if the hemin binding of $P$. endodontalis was dependent on the concentration of hemin added.

The Congo red binding assay of $P$. endodontalis proceeded in a similar way. In the Congo red binding experiment, the OD values were measured at $488 \mathrm{~nm}$ [18]. To evaluate whether the Congo red binding of $P$. endodontalis is dependent on the concentration of bacteria, Congo red binding was analyzed for various concentrations ([0-30] $\times 10^{9}$ cells $/ \mathrm{mL}$ ) of bacteria. In order to examinewhether the Congo red binding of bacteria was dependent on the amount of Congo red added, several Congo red concentrations (final concentration $0-80 \mu \mathrm{g} / \mathrm{mL}$ ) were tested.

\section{Competition analysis of hemin and Congo red}

To examine the relationship between hemin binding and Congo red binding, Congo red binding of $P$. endodontalis bound to hemin was analyzed [17]. $1 \mathrm{~mL}$ of the bacterial suspension $\left(1 \times 10^{10}\right.$ cells $\left./ \mathrm{mL}\right)$ and $0.5 \mathrm{~mL}$ of hemin (final concentration 0-40 $\mu \mathrm{g} / \mathrm{mL}$ ) (Sigma-Aldrich) were incubated in a $37^{\circ} \mathrm{C}$ water bath for 30 minutes and then centrifuged $\left(12,000 \times \mathrm{g}, 4^{\circ} \mathrm{C}, 10\right.$ minutes). The bacterial pellet was washed twice with PBS and then resuspended in $1 \mathrm{~mL}$ of PBS. Bacterial suspension was incubated with $0.5 \mathrm{~mL}$ of Congo red (final concentration $40 \mu \mathrm{g} / \mathrm{mL}$ ) (Sigma-Aldrich) in a $37^{\circ} \mathrm{C}$ water bath for 30 minutes. The OD value of the supernatant was measured by a spectrophotometer at 488 $\mathrm{nm}$ after centrifugation $\left(12,000 \times \mathrm{g}, 4^{\circ} \mathrm{C}, 10\right.$ minutes) [17].

\section{Sodium dodecyl sulfate-polyacrylamide gel electrophoresis (SDS-PAGE)}

In order to identify the hemin binding proteins involved in the hemin binding of $P$. endodontalis, SDS-PAGE analysis was carried out by binding hemin-agarose beads to bacterial proteins according to the procedure described by Tai et al. [19]. $50 \mathrm{~mL}$ of $P$. endodontalis cultured for 48 hours was centrifuged (12,000 $\times \mathrm{g}, 4^{\circ} \mathrm{C}, 10$ minutes) and then washed twice with PBS to obtain bacterial pellet. The bacterial pellet was resuspended in $10 \mathrm{~mL}$ of Tris- $\mathrm{NaCl}$ buffer (TN buffer) (50 mM Tris+1 M NaCl, pH 8.0) and kept on ice for 10 minutes. The cells were then lyzed with an ultrasonicator (Sonics \& Materials, Newtown, CT, USA) (kept on ice intermittently for 30 seconds). After centrifugation $(12,000 \times$ g, $4^{\circ} \mathrm{C}, 10$ minutes), $1 \mathrm{~mL}$ of the supernatant was incubated with $50 \mu \mathrm{L}$ of hemin-agarose beads (Sigma-Aldrich) in a $37^{\circ}$ $\mathrm{C}$ water bath for 1 hour. After centrifugation $\left(12,000 \times \mathrm{g}, 4^{\circ}\right.$ C, 10 minutes), the supernatant was removed. After resuspension in $1 \mathrm{~mL}$ of Tris-NaCl buffer ( $\mathrm{pH}$ 8.0) containing 10 $\mathrm{mM}$ EDTA and $0.75 \%$ Sarcosyl, the cells were centrifuged $\left(7,000 \times \mathrm{g}, 4^{\circ} \mathrm{C}, 3\right.$ minutes). After removing the supernatant, the beads were resuspended in $1 \mathrm{~mL}$ of $10 \mathrm{mM}$ Tris- $\mathrm{HCl}(\mathrm{pH}$ 8.0) supplemented with $1 \mathrm{M} \mathrm{NaCl}, 10 \mathrm{mM}$ EDTA, and 0.5\% Sarcosyl, followed by centrifugation $\left(7,000 \times \mathrm{g}, 4^{\circ} \mathrm{C}, 3 \mathrm{~min}-\right.$ utes) (repeated thrice). The supernatant was removed and the beads were resuspended in $1 \mathrm{~mL}$ of $50 \mathrm{mM}$ Tris- $\mathrm{HCl}(\mathrm{pH}$ 8.0) containing $1 \mathrm{M} \mathrm{NaCl}$, followed by centrifugation $(7,000$ $\times \mathrm{g}, 4^{\circ} \mathrm{C}, 3$ minutes) (repeated twice). The supernatant was removed and the beads were resuspended by adding $1 \mathrm{~mL}$ of TN buffer ( $\mathrm{pH} 8.0$ ), followed by centrifugation $(7,000$ $\times \mathrm{g}, 4^{\circ} \mathrm{C}, 3$ minutes). The supernatant was removed and the 
remaining beads were dissolved in $2 \mathrm{X}$ sample buffer (half of the beads volume) and heated at $100^{\circ} \mathrm{C}$ for 5 minutes to prepare a hemin binding protein sample. $20 \mu \mathrm{L}$ of the prepared sample was electrophoresed in 10\% polyacrylamide gel (KOMABIOTECH, Seoul, Korea) and stained with Coomassie brilliant blue (Sigma-Aldrich) [19].

\section{Statistical analysis}

Statistical significance was determined using a two-sample Student t-test. Student t-test was conducted through the Software Package for Social Sciences (SPSS version 23, IBM Corp., Armonk, NY, USA) program.

\section{Results}

\section{Growth test}

In order to investigate whether P. endodontalis could actually obtain iron through hemin and use it for growth, growth experiments were carried out using NTA, an ironchelator (Fig. 1). Growth analysis showed that the growth of $P$. endodontalis was observed with a doubling time of about 6 hours in the basal medium without any treatment.

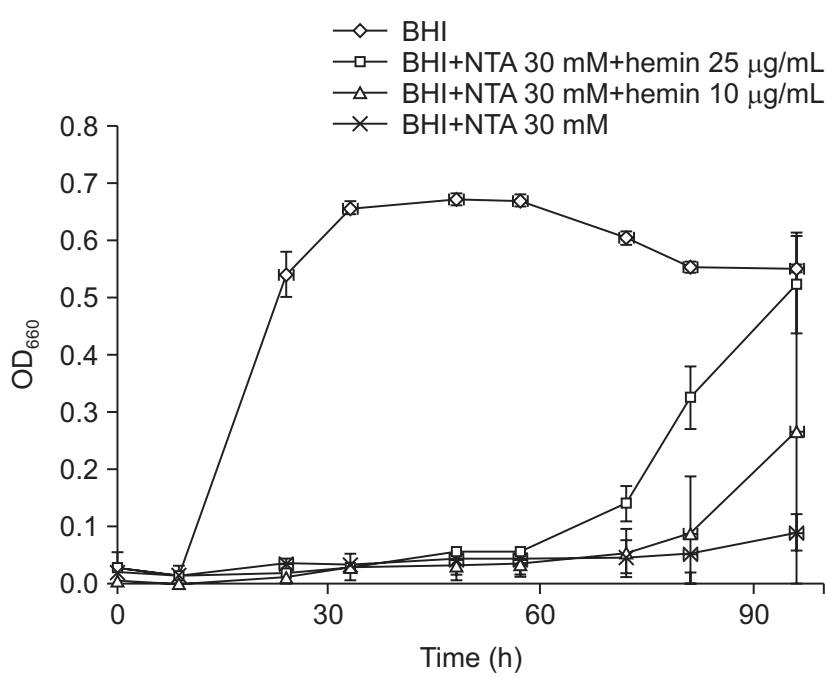

Fig. 1. Growth curve of $P$. endodontalis ATCC 35406. P. endodontalis grown in Brain Heart Infusion (BHI) medium $(\diamond)$ and in nitrilotriacetic acid trisodium salt (NTA)-treated (iron-depleted) Brain Heart Infusion medium without addition of hemin $(x)$; with hemin $(10 \mu \mathrm{g} /$ $\mathrm{mL})(\triangle)$; or with hemin $(25 \mu \mathrm{g} / \mathrm{mL})(\square)$. Values indicate means of duplicates and the vertical bars denote the standard deviation.
Growth of $P$. endodontalis in NTA-treated media was drastically reduced. However, when hemin was added to NTAtreated medium, growth of bacteria was restored. Bacterial growth in this medium was slower than that in the basal medium. However, the absorbance at the time of maximum growth (hemin $25 \mu \mathrm{g} / \mathrm{mL}$ ) was similar to that of the basal medium. In addition, as the concentration of hemin added to the medium increased, the absorbance of the supplemented medium increased proportionately (Fig. 1).

\section{Hemin binding and Congo red binding analysis}

To examine whether the hemin binding ability of $P$. endodontalis is dependent on the bacterial concentration, hemin binding was analyzed at several bacterial concentrations. As a result, the amount of hemin bound to $P$. endodontalis increased in proportion to the concentration of bacteria (Fig. 2). Moreover, the hemin binding ability of bacteria was dependent on the amount of hemin added. However, when hemin was added at a specific concentration $(40 \mu \mathrm{g} / \mathrm{mL})$ or more, there was no significant difference in the amount of hemin bound to bacteria (Fig. 3). We also

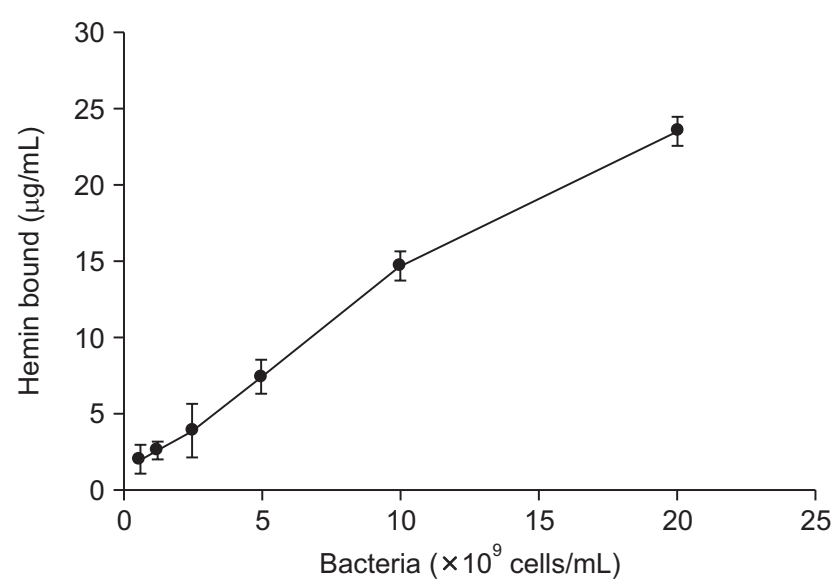

Fig. 2. Effects of bacterial concentration on Hemin binding of $P$. endodontalis ATCC 35406 . P. endodontalis cells $\left(0-20 \times 10^{9}\right.$ cells $\left./ \mathrm{mL}\right)$ were incubated with hemin at $37^{\circ} \mathrm{C}$. After incubation of the mixture for $30 \mathrm{~min}$, the binding reactions were terminated by centrifugation at $12,000 \times \mathrm{g}$ for $10 \mathrm{~min}$. The quantity of unbound hemin remaining in the supernatant was measured at $400 \mathrm{~nm}$ with a spectrophotometer. The amount of hemin bound to $P$. endodontalis was calculated as the difference between the amount of hemin added and the amount of hemin remaining in the supernatant after reaction. Values indicate means of duplicates and the vertical bars denote the standard deviation. 


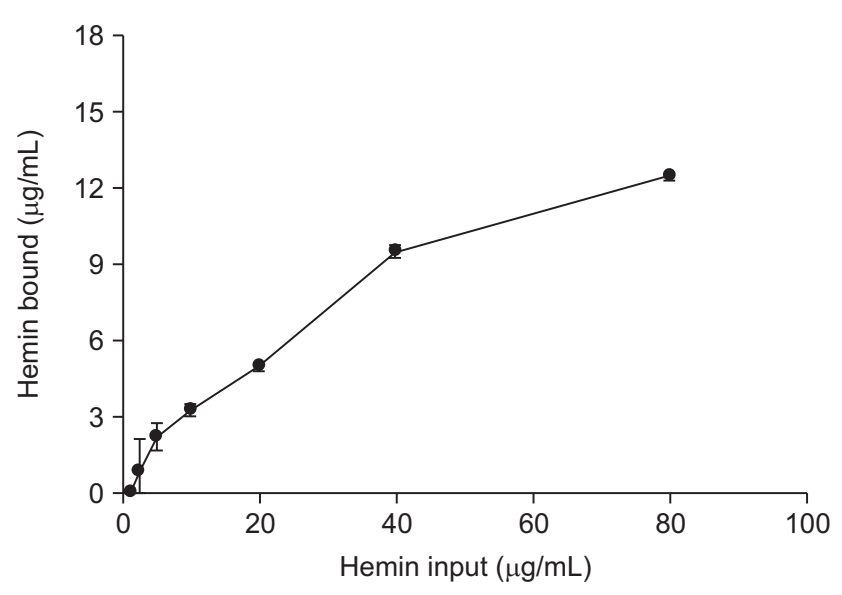

Fig. 3. Effects of Hemin concentration on Hemin binding of $P$. endodontalis ATCC 35406. The reaction mixture contained $1 \mathrm{~mL}$ of bacterial suspension $\left(\mathrm{OD}_{660}=1.5\right)$ and $0.5 \mathrm{~mL}$ hemin (final concentration $0-80 \mu \mathrm{g} / \mathrm{mL}$ ). After incubation of the mixture at $37^{\circ} \mathrm{C}$ for $30 \mathrm{~min}$, the binding reactions were terminated by centrifugation at $12,000 \times \mathrm{g}$ for $10 \mathrm{~min}$. The quantity of unbound hemin remaining in the supernatant was measured at $400 \mathrm{~nm}$ with a spectrophotometer. The amount of hemin bound to $P$. endodontalis was calculated as the difference between the amount of hemin added and the amount of hemin remaining in the supernatant after reaction. Values indicate means of duplicates and the vertical bars denote the standard deviation. If the standard deviation value is too small, the error bar is obscured by the point.

analyzed the hemin binding capacity of $P$. endodontalis at several incubation temperatures to check whether the hemin binding capacity of the bacteria differs depending on the incubation temperature. Hemin binding of bacteria did not show any significant difference with change in the incubation temperature (Fig. 4). Although the amount of hemin bound to bacteria increased with incubation time, no significant difference was observed between the values obtained for 10 minutes incubation and 30 minutes incubation (Fig. 5).

Congo red binding was analyzed at several bacterial concentrations to check whether the Congo red binding of $P$. endodontalis depends on the concentration of bacteria. As a result, Congo red binding increased in proportion to the concentration of bacteria (Fig. 6). In addition, experiments were carried out at various Congo red concentrations to determine whether the Congo red binding of $P$. endodontalis is dependent on the amount of Congo red added. The Congo red binding of the bacteria was shown to be increased upon increase in the concentration of added Congo red (Fig. 7).

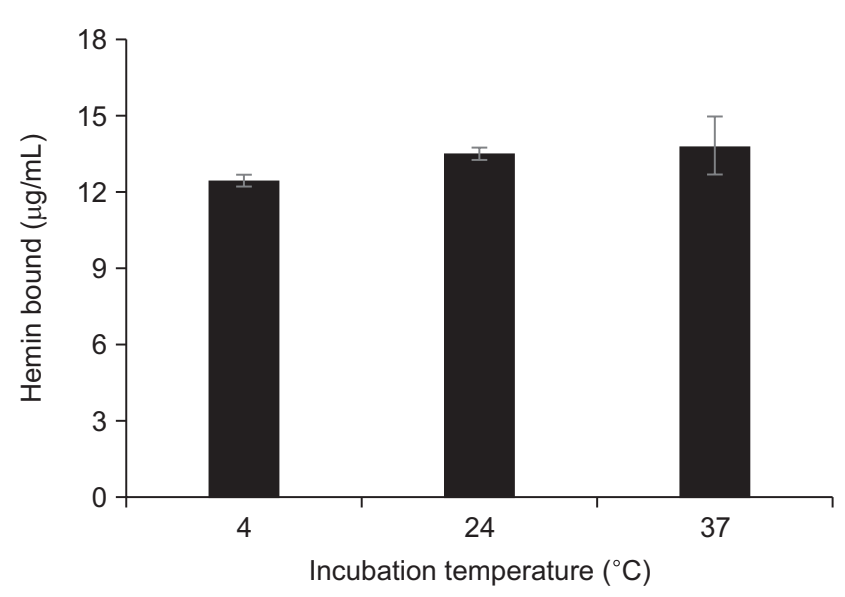

Fig. 4. Effects of incubation temperature on hemin binding of $P$. endodontalis ATCC 35406. P. endodontalis cells $\left(1 \times 10^{10}\right.$ cells $\left./ \mathrm{mL}\right)$ were bound to hemin for $30 \mathrm{~min}$ at $4^{\circ} \mathrm{C}, 25^{\circ} \mathrm{C}$, and $37^{\circ} \mathrm{C}$, respectively. Values indicate means of duplicates and the vertical bars denote the standard deviation.

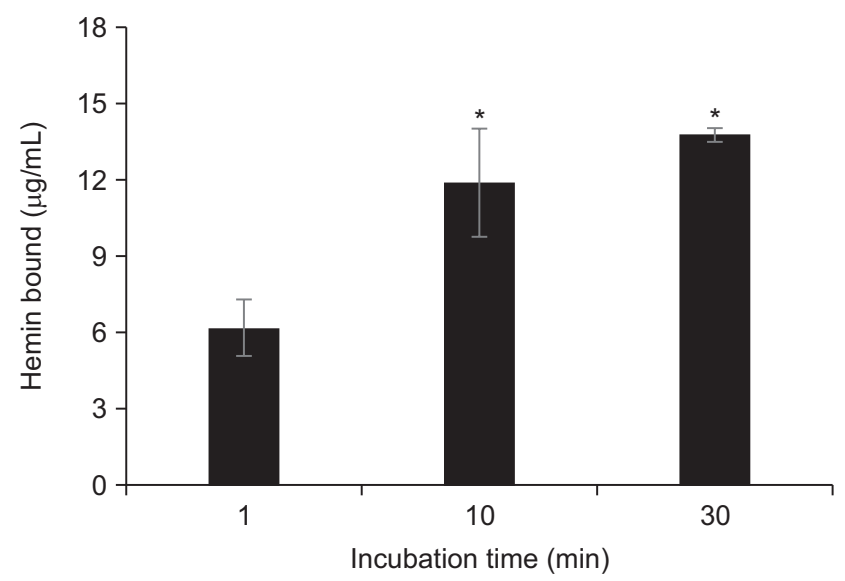

Fig. 5. Effects of incubation time on hemin binding of $P$. endodontalis ATCC 35406 . $P$. endodontalis ATCC 35406 cells $\left(1 \times 10^{10}\right.$ cells/ $\mathrm{mL}$ ) were bound to hemin at $37^{\circ} \mathrm{C}$ for $1 \mathrm{~min}, 10 \mathrm{~min}$, and $30 \mathrm{~min}$, respectively. Values indicate means of duplicates and the vertical bars denote the standard deviation. Statistically significances were considered as $p$-values of $\leq 0.05$ and were indicated by ${ }^{*}$.

\section{Competition analysis of hemin and Congo red}

Congo red binding was analyzed after binding of $P$. endodontalis with hemin in order to examine the association between hemin binding and Congo red binding in $P$. endodontalis. As a result, Congo red binding of $P$. endodontalis was inhibited by about $21.4 \%$ when $2.5 \mu \mathrm{g} / \mathrm{mL}$ hemin was pre-bound and about $39.5 \%$ when $10 \mu \mathrm{g} / \mathrm{mL}$ hemin was prebound. When hemin was pre-bound at a concen- 


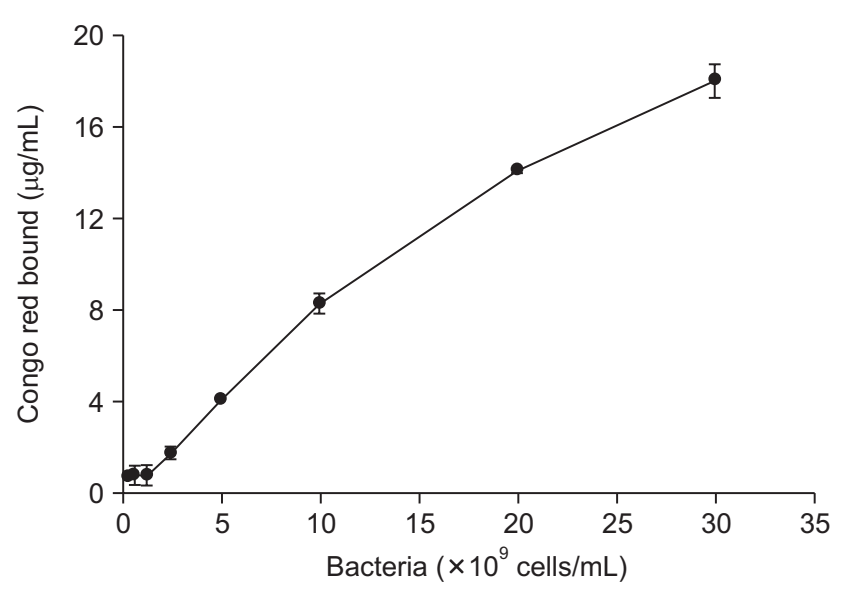

Fig. 6. Effects of bacterial concentration on Congo red binding of P. endodontalis ATCC 35406 . P. endodontalis cells $\left(0-30 \times 10^{9}\right.$ cells/ $\mathrm{mL}$ ) were incubated with Congo red at $37^{\circ} \mathrm{C}$. After incubation of the mixture for $30 \mathrm{~min}$, the binding reactions were terminated by centrifugation at $12,000 \times \mathrm{g}$ for $10 \mathrm{~min}$. The quantity of unbound Congo red remaining in the supernatant was measured at $488 \mathrm{~nm}$ with a spectrophotometer. The amount of Congo red bound was determined by measuring the amount of dye remaining in the supernatant. Values indicate means of duplicates and the vertical bars denote the standard deviation. If the standard deviation value is too small, the error bar is obscured by the point.

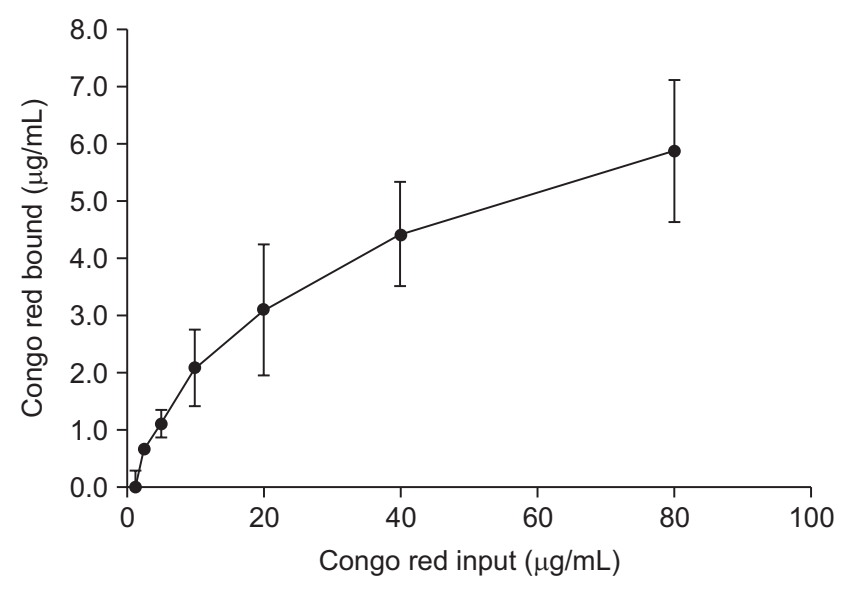

Fig. 7. Effects of Congo red concentration on Congo red binding of $P$. endodontalis ATCC 35406. The reaction mixture contained $1 \mathrm{~mL}$ of bacterial suspension $\left(\mathrm{OD}_{660}=1.5\right)$ and $0.5 \mathrm{~mL}$ Congo red (final concentration $0-80 \mu \mathrm{g} / \mathrm{mL}$ ). After incubation of the mixture at $37^{\circ} \mathrm{C}$ for $30 \mathrm{~min}$, bacteria were removed by centrifugation, and the amount of Congo red bound was determined by measuring the amount of dye remaining in the supernatant. Values indicate means of duplicate experiments and the error bars indicate standard deviations of the mean.

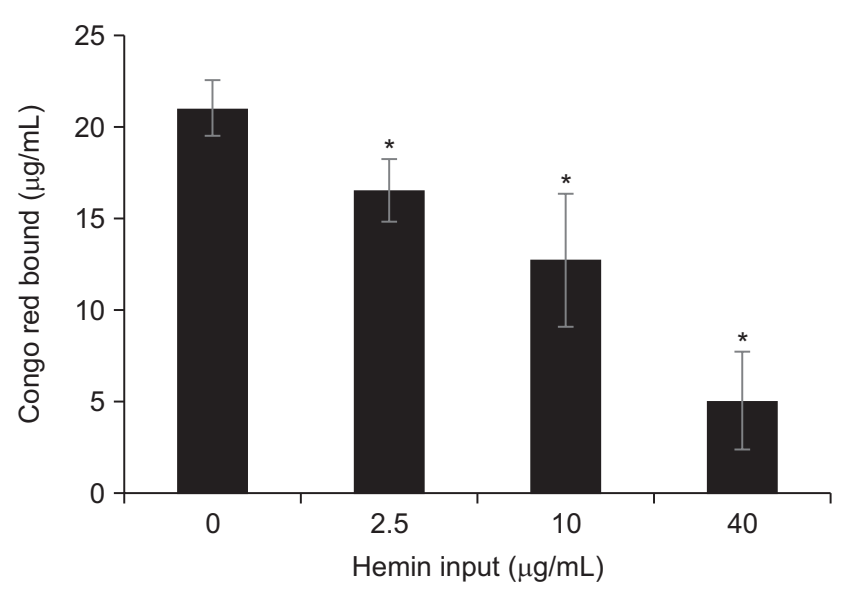

Fig. 8. Inhibition of Congo red binding of $P$. endodontalis ATCC 35406 by hemin prebinding. Hemin was allowed to prebind to $P$. endodontalis, and the excess hemin was removed by washing with PBS, followed by the addition of Congo red (final concentration 40 $\mu \mathrm{g} / \mathrm{mL}$ ). Amount of Congo red bound to bacteria was measured with a spectrophotometer. Values indicate means of duplicate experiments and the error bars indicate standard deviations of the mean. Statistically significances were considered as $p$-values of $\leq 0.05$ and were indicated by ${ }^{*}$.

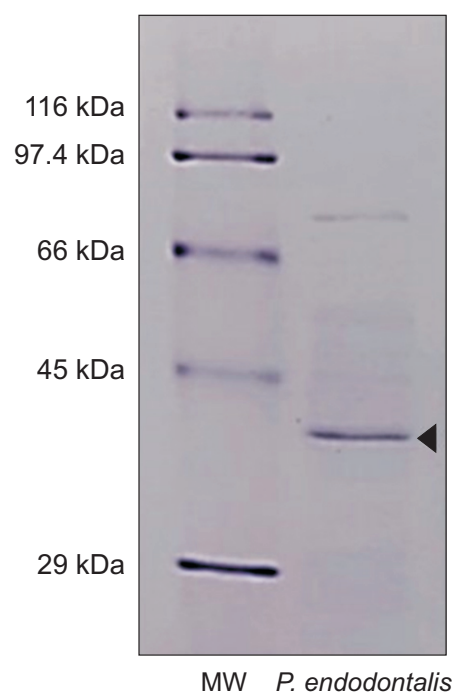

Fig. 9. SDS-PAGE analysis of hemin binding protein of $P$. endodontalis ATCC 35406. Bacterial components bound to hemin-agarose beads were extracted from $P$. endodontalis. The samples were analyzed by SDS-PAGE with Coomassie Brilliant blue staining. Lane 1 (molecular weight markers) represents the mass $(\mathrm{kDa})$ of a protein molecule. Lane 2 represents the hemin binding protein of $P$. endodontalis. 
tration of $40 \mu \mathrm{g} / \mathrm{mL}$, it was confirmed that the inhibition was about $76 \%$ (Fig. 8).

\section{Sodium dodecyl sulfate-polyacrylamide gel electrophoresis (SDS-PAGE)}

In order to identify proteins involved in hemin binding of $P$. endodontalis, hemin-agarose beads were bound to bacterial proteins and SDS-PAGE analysis was performed. The band of protein presumed to be involved in the hemin binding of $P$. endodontalis was observed at $40 \mathrm{kDa}$ (Fig. 9).

\section{Discussion}

Porphyromonas genus requires iron for growth [13], and bacteria have a mechanism for obtaining iron from the environment [3]. Heme compounds can supply enough iron to grow [8], and it has been shown that iron can be obtained from hemin in $P$. gingivalis $[8,18,20]$. In this study, the growth of $P$. endodontalis in NTA-treated media was drastically reduced. However, when hemin was added to NTA-treated medium, growth of $P$. endodontalis was restored. This observation supports the possibility that $P$. endodontalis can obtain iron required for growth using hemin. The ability to use heme compounds such as hemin or hemoglobin has been implicated in the binding of these molecules to bacteria, as revealed by studies on bacteria that require hemin for growth [21]. The hemin binding of $P$. endodontalis was dependent on the bacterial concentration and the concentration of hemin added. However, when the concentration of hemin above a certain value was used, the change in the hemin binding ability of the bacteria was insignificant. This suggests that bacteria can bind to a certain amount of hemin and that a certain number of hemin binding sites exist in a single bacterium.

Previous studies have shown that Congo red binding is inhibited by hemin and protophorphyrin IX [15]. In this study, Congo red binding of $P$. endodontalis was dependent on bacterial concentration and concentration of added Congo red. However, when the amount of added Congo red was above a certain level, the degree of Congo red binding decreased gradually. These results indicate that bacteria can bind only to a certain amount of Congo red.
In addition, when $P$. endodontalis was prebound to hemin before Congo red binding, Congo red binding of bacteria was reduced by about $76 \%$. Studies on the association between hemin and Congo red binding have been conducted in several bacteria. Daskaleros and Payne [16] showed that S. flexneri inhibited Congo red binding by more than $30 \%$ when bound to hemin before binding to Congo red. In addition, Kay et al. [22] showed that Congo red binding of Aeromonas salmonicida was inhibited by more than $40 \%$ when hemin was prebound. This Congo red and hemin competition analysis suggests that these two compounds can bind to the same or closely related sites in bacteria. Nevertheless, when hemin was prebound, Congo red was still bound to bacteria, although the Congo red of bacteria binding was inhibited. There are a few possible reasons for this observation. First, the molecular structure of Congo red and hemin is similar, but not identical, and Congo red can additionally bind to the hemin-bound receptors of bacteria [16]. Second, an assumption is made that these two compounds can bind to distinct sites other than the common binding site on bacterial surfaces [16]. Third, hemin is weakly bound to bacteria, and after the hemin has detached from the bacteria, the Congo red may bind to the site.

Several previous studies have shown that proteins are involved in the hemin binding of bacteria [23,24]. A 39.5 $\mathrm{kDa}$ protein was identified as a protein involved in the hemin binding of Haemophilus influenzae [23]. In addition, in Vibrio vulnificus, a $36.5 \mathrm{kDa}$ protein is involved in hemin binding [24]. And a $40 \mathrm{kDa}$ protein located in the outer membrane of $P$. gingivalis was found to be involved in hemin binding [20]. According to this study, the $40 \mathrm{kDa}$ protein of $P$. gingivalis was essential for the growth of bacteria in hemin-depleted environments [20]. In this study, protein predicted to be involved in the hemin binding of P. endodontalis was observed at $40 \mathrm{kDa}$. It is not known whether the $40 \mathrm{kDa}$ protein found in $P$. endodontalis and the $40 \mathrm{kDa}$ protein previously reported in $P$. gingivalis are identical.

Recently, Gao et al. [25] identified an $18 \mathrm{kDa}$ protein from $P$. gingivalis, which is different from the previously found $40 \mathrm{kDa}$ hemin binding protein (HBP35) [20]. This protein has been identified as a Dps (DNA binding protein from 
starved cells) protein homolog. According to these studies, Dps of P. gingivalis could bind to hemin. In addition, Yamamoto et al. [26] identified a Dpr (20 kDa), Dps family protein, in Streptococcus mutans. The Dpr protein is structurally similar to the Dps protein and has been reported to bind iron. According to Mieno et al. [27], Dpr of $S$. mutans and Dps of $P$. gingivalis could be evolved as members of a hemin binding family. Therefore, further studies are needed to confirm the possibility that the hemin-binding protein (40 kDa) of P. endodontalis has evolved from Dps family proteins.

The presence of hemin in the growth environment of bacteria is related to bacterial virulence. According to the study by Love [28], hemin influences bacterial penetration into the dentinal tubule. Peptostreptococcus micros and Prevotella intermedia could invade into the dentinal tubules when incubated in the presence of hemin, but not when hemin was absent [28]. These results suggest that the presence of hemin can increase bacterial invasion.

Hemin is likely to be present in dentinal tubules in the free form or in the form bound to heme compounds, which were released from damaged red blood cells [28]. In addition, heme compounds were found in the gingival crevicular fluid and gingiva [29]. Heme compounds are degraded by acids to form hemin [30]. In addition, hemin may be present in root canal environment due to the influx of blood during endodontic treatment [31]. Thus, the ability of $P$. endodontalis residing in root canal to bind to hemin is likely to play an important role in the growth of this bacterium.

In this study, we analyzed the hemin binding properties of $P$. endodontalis and confirmed the association of Congo red and hemin binding in this bacterium. In addition, SDSPAGE analysis using hemin agarose beads confirmed the presence of proteins involved in hemin binding. It was confirmed that $P$. endodontalis could grow by obtaining iron through hemin. In order to clearly understand the mechanism of iron uptake in $P$. endodontalis, further studies such as analysis of structure and localization of hemin binding protein and study of mechanism of iron migration in bacteria are needed.

\section{Conflicts of Interest}

The authors declare that they have no competing interests.

\section{ORCID}

\author{
Eun Jeong Kim \\ https://orcid.org/0000-0001-7380-7698 \\ Si Young Lee \\ https://orcid.org/0000-0001-8826-1413
}

\section{References}

1. Weinberg ED. Iron and infection. Microbiol Rev 1978;42: 45-66.

2. Griffiths E, Stevenson P, Joyce P. Pathogenic Escherichia coli express new outer membrane proteins when growing in vivo. FEMS Microbiol Lett 1983;16:95-99.

3. Wooldridge KG, Williams PH. Iron uptake mechanisms of pathogenic bacteria. FEMS Microbiol Rev 1993;12:325348. doi: 10.1111/j.1574-6976.1993.tb00026.x.

4. Vagrali MA. Siderophore production by uropathogenic Escherichia coli. Indian J Pathol Microbiol 2009;52:126127. doi: $10.4103 / 0377-4929.44988$.

5. Snow GA. Mycobactins: iron-chelating growth factors from mycobacteria. Bacteriol Rev 1970;34:99-125.

6. Russell LM, Holmes RK. Initial characterization of the ferric iron transport system of Corynebacterium diphtheriae. J Bacteriol 1983;155:1439-1442. doi: 10.1128/ JB.155.3.1439-1442.1983.

7. Hanson MS, Hansen EJ. Molecular cloning, partial purification, and characterization of a haemin-binding lipoprotein from Haemophilus influenzae type b. Mol Microbiol 1991;5:267-278. doi: 10.1111/j.1365-2958.1991.tb02107. $\mathrm{x}$.

8. Bramanti TE, Holt SC. Roles of porphyrins and host iron transport proteins in regulation of growth of Porphyromonas gingivalis W50. J Bacteriol 1991;173:7330-7339. doi: 10.1128/jb.173.22.7330-7339.1991.

9. Xu X, Holt SC, Kolodrubetz D. Cloning and expression of two novel hemin binding protein genes from Treponema denticola. Infect Immun 2001;69:4465-4472. doi: 10.1128/ IAI.69.7.4465-4472.2001.

10. Graber KR, Smoot LM, Actis LA. Expression of iron binding proteins and hemin binding activity in the dental pathogen Actinobacillus actinomycetemcomitans. FEMS Microbiol Lett 1998;163:135-142. doi: 10.1111/j.1574-6968.1998. tb13037.x.

11. Worst DJ, Otto BR, de Graaff J. Iron-repressible outer membrane proteins of Helicobacter pylori involved in 
heme uptake. Infect Immun 1995;63:4161-4165. doi: 10.1128/IAI.63.10.4161-4165.1995.

12. Stoebner JA, Payne SM. Iron-regulated hemolysin production and utilization of heme and hemoglobin by Vibrio cholerae. Infect Immun 1988;56:2891-2895. doi: 10.1128/ IAI.56.11.2891-2895.1988.

13. van Winkelhoff AJ, van Steenbergen TJ, Kippuw N, De Graaff J. Further characterization of Bacteroides endodontalis, an asaccharolytic black-pigmented Bacteroides species from the oral S cavity. J Clin Microbiol 1985;22:75-79. doi: 10.1128/JCM.22.1.75-79.1985.

14. Surgalla MJ, Beesley ED. Congo red-agar plating medium for detecting pigmentation in Pasteurella pestis. Appl Microbiol 1969;18:834-837.

15. Scott D, Siboo IR, Chan EC, Klitorinos A, Siboo R. Binding of hemin and congo red by oral hemolytic spirochetes. Oral Microbiol Immunol 1993;8:245-250. doi: 10.1111/j.1399302x.1993.tb00568.x.

16. Daskaleros PA, Payne SM. Congo red binding phenotype is associated with hemin binding and increased infectivity of Shigella flexneri in the HeLa cell model. Infect Immun 1987;55:1393-1398. doi: 10.1128/IAI.55.6.13931398.1987.

17. Eichenbaum Z, Green BD, Scott JR. Iron starvation causes release from the group A streptococcus of the ADPribosylating protein called plasmin receptor or surface glyceraldehyde-3-phosphate-dehydrogenase. Infect Immun 1996;64:1956-1960. doi: 10.1128/IAI.64.6.19561960.1996.

18. Genco CA, Odusanya BM, Brown G. Binding and accumulation of hemin in Porphyromonas gingivalis are induced by hemin. Infect Immun 1994;62:2885-2892. doi: 10.1128/ IAI.62.7.2885-2892.1994.

19. Tai SS, Wang TR, Lee CJ. Characterization of hemin binding activity of Streptococcus pneumoniae. Infect Immun 1997;65:1083-1087. doi: 10.1128/IAI.65.3.10831087.1997.

20. Shoji M, Shibata Y, Shiroza T, Yukitake H, Peng B, Chen YY, Sato K, Naito M, Abiko Y, Reynolds EC, Nakayama K. Characterization of hemin-binding protein 35 (HBP35) in Porphyromonas gingivalis: its cellular distribution, thioredoxin activity and role in heme utilization. BMC Microbiol 2010;10:152. doi: 10.1186/1471-2180-10-152.

21. Payne SM. Iron and virulence in the family Enterobacteriaceae. Crit Rev Microbiol 1988;16:81-111. doi:
10.3109/10408418809104468.

22. Kay WW, Phipps BM, Ishiguro EE, Trust TJ. Porphyrin binding by the surface array virulence protein of Aeromonas salmonicida. J Bacteriol 1985;164:1332-1336. doi: 10.1128/JB.164.3.1332-1336.1985.

23. Lee BC. Isolation of an outer membrane hemin-binding protein of Haemophilus influenzae type b. Infect Immun 1992;60:810-816. doi: 10.1128/IAI.60.3.810-816.1992.

24. Fouz B, Mazoy R, Vázquez F, Lemos ML, Amaro C. Isolation of a hemin and hemoglobin binding outer membrane protein of Vibrio vulnificus biotype 2 (serogroup E). FEMS Microbiol Lett 1997;156:187-191. doi: 10.1111/j.15746968.1997.tb12725.x.

25. Gao JL, Lu Y, Browne G, Yap BC, Trewhella J, Hunter N, Nguyen KA. The role of heme binding by DNA-protective protein from starved cells (Dps) in the Tolerance of Porphyromonas gingivalis to heme toxicity. J Biol Chem 2012;287:42243-42258. doi: 10.1074/jbc.M112.392787.

26. Yamamoto Y, Poole LB, Hantgan RR, Kamio Y. An ironbinding protein, Dpr, from Streptococcus mutans prevents iron-dependent hydroxyl radical formation in vitro. J Bacteriol 2002;184:2931-2939. doi: 10.1128/jb.184.11.29312939.2002.

27. Mieno A, Yamamoto Y, Yoshikawa Y, Watanabe K, Mukai $\mathrm{T}$, Orino K. Binding analysis of ferritin with heme using $\alpha$-casein and biotinylated-hemin: detection of heme-binding capacity of Dpr derived from heme synthesis-deficient Streptococcus mutans. J Vet Med Sci 2013;75:1101-1105. doi: 10.1292/jvms.13-0095.

28. Love RM. Hemin nutritional stress inhibits bacterial invasion of radicular dentine by two endodontic anaerobes. Int Endod J 2007;40:94-99. doi: 10.1111/j.13652591.2006.01186.x.

29. Smalley JW, Birss AJ, McKee AS, Marsh PD. Haemin binding as a factor in the virulence of Porphyromonas gingivalis. FEMS Microbiol Lett 1996;141:65-70. doi: 10.1111/j.15746968.1996.tb08364.x.

30. Bonkovsky HL, Guo JT, Hou W, Li T, Narang T, Thapar M. Porphyrin and heme metabolism and the porphyrias. Compr Physiol 2013;3:365-401. doi: 10.1002/cphy.c120006.

31. Zerr MA, Cox CD, Johnson WT, Drake DR. Effect of red blood cells on the growth of Porphyromonas endodontalis and microbial community development. Oral Microbiol Immunol 1998;13:106-112. doi: 10.1111/j.1399-302x.1998. tb00720.x. 